\title{
PMDA's Initiatives Based on Regulatory Science. In Pursuit of Developing Innovative Drugs and Medical Devices
}

\section{Tatsuya Kondo}

Pharmaceuticals and Medical Devices Agency, Japan

The Pharmaceuticals and Medical Devices Agency (PMDA) is an independent administrative agency which carries out relief services for persons suffering from adverse health effects, product reviews, and safety measures based on Pharmaceuticals and Medical Devices Act. The activities of PMDA are based on the idea of regulatory science. In this presentation, I will introduce PMDA's international activities and its initiative to develop innovative medicines and medical devices. As a result of the resolution of the drug and medical device lag, PMDA is highly appreciated internationally as well, and is expected to contribute further internationally. 